\title{
Climate risk to European fisheries and coastal communities
}

\author{
Payne, Mark R.; Kudahl, Manja; Engelhard, Georg H.; Peck, Myron A.; Pinnegar, John K.
}

Published in:

Proceedings of the National Academy of Sciences of the United States of America

Link to article, DOI:

10.1073/pnas.2018086118

Publication date:

2021

Document Version

Early version, also known as pre-print

Link back to DTU Orbit

Citation (APA):

Payne, M. R., Kudahl, M., Engelhard, G. H., Peck, M. A., \& Pinnegar, J. K. (2021). Climate risk to European fisheries and coastal communities. Proceedings of the National Academy of Sciences of the United States of America, 118(40), [e2018086118]. https://doi.org/10.1073/pnas.2018086118

\section{General rights}

Copyright and moral rights for the publications made accessible in the public portal are retained by the authors and/or other copyright owners and it is a condition of accessing publications that users recognise and abide by the legal requirements associated with these rights.

- Users may download and print one copy of any publication from the public portal for the purpose of private study or research.

- You may not further distribute the material or use it for any profit-making activity or commercial gain

- You may freely distribute the URL identifying the publication in the public portal 


\title{
1 Climate risk to European fisheries and coastal communities
}

2

\author{
Mark R. Payne $^{1 *}$, Manja Kudahl ${ }^{1}$, Georg H. Engelhard ${ }^{2,3}$, Myron A. Peck ${ }^{4}$ and John K. Pinnegar ${ }^{2,3}$
}

1. National Institute of Aquatic Resources (DTU-Aqua), Technical University of Denmark, 2800 Kgs. Lyngby, Denmark.

2. Centre for Environment, Fisheries \& Aquaculture Science (Cefas), Pakefield Road, Lowestoft, United Kingdom

3. School of Environmental Sciences, University of East Anglia (UEA), Norwich, United Kingdom

4. Department of Coastal Systems, Royal Netherlands Institute for Sea Research (NIOZ), PO Box 59, 1790 AB Den Burg (Texel), the Netherlands

*Corresponding author.

Mark R. Payne

National Institute of Aquatic Resources (DTU-Aqua)

Technical University of Denmark

2800 Kgs. Lyngby

Denmark

Tel.: +4533963455

ORCID: 0000-0001-5795-2481

E-mail address: mpay@aqua.dtu.dk

Keywords: hazard, exposure, vulnerability, risk, climate change, fleets

\section{Abstract}

With the majority of the global human population living in coastal regions, correctly characterising the climate risk that ocean-dependent communities and businesses are exposed to is key to prioritising the finite resources available to support adaptation. We apply a climate risk analysis across the European fisheries sector for the first time to identify the most at-risk fishing fleets and coastal regions and then link the two analyses together. We employ a novel approach combining biological traits with physiological metrics to differentiate climate hazards between 556 populations of fish and use these to assess the relative climate risk for 380 fishing fleets and 105 coastal regions in Europe. Countries in southeast Europe as well as the UK have the highest risks to both fishing fleets and coastal regions overall while, in other countries, the risk-profile is greater at either the fleet level or at the regional level. European fisheries face a diversity of challenges posed by climate change and climate adaptation, therefore, needs to be tailored to each country, region and fleet's specific situation. Our analysis supports this process by highlighting where and what adaptation measures might be needed and informing where policy and business responses could have the greatest impact.

\section{Significance Statement}

We present a novel climate risk analysis for i) 105 ocean-dependent communities and ii) 380 fishing fleets in Europe. Our unique approach provides a perspective over the climate risks in this diverse and populous continent that is unprecedented in both its breadth and detail. We show that countries in 
southeast Europe as well as the UK have the highest climate risk overall, both in terms of fishing fleets and coastal communities. Substantial variation in climate risk is seen even within countries, emphasizing that climate adaptation interventions need to be tailored to the specific characteristics of the fleet or community. A focus on sustainable fisheries management and diversification of fish portfolios can reduce climate risks across the board.

\section{Main Text}

The ocean provides human societies with a wide variety of goods and services, ranging from food and employment to climate regulation and cultural nourishment (Hassan et al., 2005). Climate change is already shifting the abundance, distribution, productivity and phenology of living marine resources (Poloczanska et al., 2013; FAO, 2018; Phillips and Pérez-Ramírez, 2018), thereby impacting many of the ecosystem services upon which society depends (IPCC, 2019). These impacts, however, are not being experienced uniformly by human society but depend on the characteristics and context of the community or business affected. Raising awareness and understanding the risk to human systems is therefore a critical first step (Allison et al., 2009) to developing and prioritising appropriate adaptation options in response to the challenges of the climate crisis (Johnson et al., 2016).

Over the past decades, climate risk assessments (CRAs) and climate vulnerability assessments (CVAs) have been developed to identify and prioritise adaptation needs. The approach, developed by the Intergovernmental Panel on Climate Change (IPCC), has shifted over time from a focus on "vulnerability" to a focus on "risk" (Oppenheimer et al., 2014), in part due to criticisms of the negative framing that "vulnerability" implies (Connelly et al., 2018). The modern CRA framework (Cardona et al., 2012) considers risk as the intersection of hazard, exposure and vulnerability (Table 1). CVAs, and more recently CRAs, have been applied widely in the marine realm, for example in coastal communities in northern Vietnam (Adger, 1999), Kenya (Cinner et al., 2013) and the USA (Colburn et al., 2016), at the national level across coastal areas of the USA (Ekstrom et al., 2015; Hare et al., 2016) and Australia (Pecl et al., 2014; Fulton et al., 2017), across regions such as Pacific island nations (Bell et al., 2011; Barsley et al., 2013) and globally (Allison et al., 2009; Barange et al., 2014; Blasiak et al., 2017). Several 'best practice' guides have also been developed (Brugere and De Young, 2015; Johnson et al., 2016).

Table 1 Definitions of terms, as used in the context of this Climate Risk Analysis. These definitions are adapted for the present study from those used in the most recent IPCC report (IPCC, 2019).

\section{Term Definition used here}

Climate risk The potential for climate change to have adverse consequences for human systems, specifically for European coastal regions and fishing fleets.

Hazard $\quad$ The potential for, and severity of, climate change impacts on the unit of interest (i.e. fish and shellfish populations). Here we focus explicitly on negative impacts, following from the definition of risk as being an adverse consequence.

Exposure The sensitivity of a region or fishing fleet to the climate hazard, i.e. the likelihood of being affected by changes in the living marine resources.

Vulnerability The ability of a region or fleet to anticipate or respond to changes induced by climate hazards and to minimise, cope with and recover from the consequences. High adaptive capacity gives low vulnerability. 
CRAs and CVAs covering European waters are, however, notable by their absence from this list. This is surprising given that European waters provide over one-eighth of the world's total marine fisheries catches (FAO, 2020), and have witnessed many well-documented changes in fish abundance and distribution in response to climate change (Perry et al., 2005; Peck and Pinnegar, 2018; Baudron et al., 2020). The lack of attention to climate risk in European fisheries may be due, in part, to the previous results of global CVAs (Allison et al., 2009) that ranked European countries as having low vulnerabilities (their relative affluence giving high 'adaptive capacity' in these analyses). Yet the European region poses unique challenges when assessing climate risks due to the wide range of species, biogeographical zones and habitats linked by intertwined management structures. Fishing techniques and the scale of fisheries also vary widely, from large fleets of small vessels in the Mediterranean Sea (STECF, 2018) to some of the largest fishing vessels in the world (e.g. the 144-m long Annelies Ilena). Furthermore, although fisheries contribute very little to national GDP, food or income-security for most European countries (Peck and Pinnegar, 2018), in specific communities and regions fishing is the mainstay of employment (Natale et al., 2013). Adapting European fisheries to a changing climate, therefore, requires the development of robust analyses capable of assessing the climate risk across this extremely diverse continent.

We conducted a CRA across the European marine fisheries sector that is globally unprecedented in its span and detail, estimating the climate risk of i) coastal regions and ii) fishing fleets in linked analyses. Our analyses spanned more than 50 degrees of latitude from the Black Sea to the Arctic and encompass the United Kingdom, Norway, Iceland and Turkey in addition to the 22 coastal nations of the European Union. We developed an entirely novel approach that distinguishes fine-scale geographical differences in the climate hazard of fish and shellfish populations and, hence, the climate risk to both European coastal regions and fishing fleets. Uniquely, since both CRAs were based on the same underlying climate hazard, these analyses could be combined to compare the relative importance of this hazard to fleets and coastal regions within a country.

\section{Coastal-Region Climate Risk Analysis}

99 Our novel index of climate hazard was derived from the biological traits of the species being harvested, 100 together with modelled distribution data. Species trait data were gathered for 157 fish and shellfish 101 species harvested in European waters, representing $90.3 \%$ of the total value of landings in Europe and at 102 least $78 \%$ (and typically more than 90\%) of national value. Uniquely, we accounted for the expected large variation in climate hazard throughout a species range (i.e. from the cold to warm edges of the distribution) by focusing on "populations" (i.e. a single species in a single FAO sub-area). Populationlevel climate hazards were then defined based on estimates of the thermal-safety margin (TSM) (sensu Deutsch et al., 2008; Sunday et al., 2014; Dahlke et al., 2020) between the temperature in that subregion and the empirically-derived upper thermal preference of the species (Kesner-Reyes et al., 2012). Climate hazards were calculated for 556 "populations" in 23 FAO subareas, based on the TSM of the population and the inherent traits of the species (Cheung et al., 2005; Hare et al., 2016; Jones and Cheung, 2018).

110 We then calculated the climate risk for 105 coastal regions across 26 countries in the European continent 111 (Figure 1). Population-level climate hazards of fish were integrated to regions, weighted by the relative 112 value of landings in that region. We defined exposure metrics based on the diversity and dominance 113 (Cline et al., 2017; Pinnegar et al., 2019) of these landings, and vulnerability based on regional socio114 economic metrics (Allison et al., 2009). We focused our analysis on coastal regions, as these are the 115 communities most directly dependent on the ocean: regions far from the sea but within a coastal nation 116 were explicitly excluded (e.g. Bavaria in the south of Germany). 
117 The analysis revealed appreciable variation in the climate risk within the European continent and even 118 within a single country (Figure 1a). In the United Kingdom, for example, climate risk was greatest in the 119 north of England, while Scotland and the south of England had the least risk. Indeed, six of the 10 regions 120 with the highest climate risk, including the overall top region (Tees Valley \& Durham), were in the UK 121 (Table S8). These results were strongly influenced by high hazard scores for the species landed in these 122 regions (Figure 1b), combined with high vulnerability due to low GDP per capita in some of these 123 regions.

124 Larger-scale patterns in climate risk were also apparent. South-east Europe stood out with consistently 125 high climate risk, with coastal Romania and Croatia in the top five. Both countries had high vulnerability 126 scores due to low GDP per capita of their coastal regions (Figure 1b, Figure S1), and high exposure scores 127 due to fisheries that target only a few species (e.g. the value of Romania's fisheries is more than 70\% 128 veined rapa whelk, Rapana venosa). Many northern European nations, including Belgium, the 129 Netherlands and Scandinavian nations had relatively low climate risks due to their wealth (high GDP per 130 capita), diverse fisheries and the relatively low climate hazard of the fish populations targeted (Figure 131 S1).

132 These overall climate-risk scores were heavily influenced by the elements (hazard, exposure or 133 vulnerability) that comprise their risk profile (Figure 1b; Figure S1). The climate risk profiles of south134 east Europe, the Iberian peninsula and some regions on the south coast of the Baltic Sea were dominated 135 by the vulnerability dimension, reflecting the low GDP per capita of these regions. For the most part, 136 exposure scores were important in Northern Europe and in Scandinavia, reflecting the narrower range of 137 species landed compared to the Mediterranean region. The climate risk of Iceland, the UK, and parts of 138 France or northern Italy, on the other hand, were dominated by the climate hazard component, i.e. the 139 traits and thermal preferences of the species targeted. The relative contributions of the individual 140 components are critical to understanding the climate risk of each country and the suitability of particular 141 adaptation responses. 
bioRxiv preprint doi: https://doi.org/10.1101/2020.08.03.234401; this version posted June 29, 2021. The copyright holder for this preprint (which was not certified by peer review) is the author/funder, who has granted bioRxiv a license to display the preprint in perpetuity. It is made available under aCC-BY 4.0 International license.

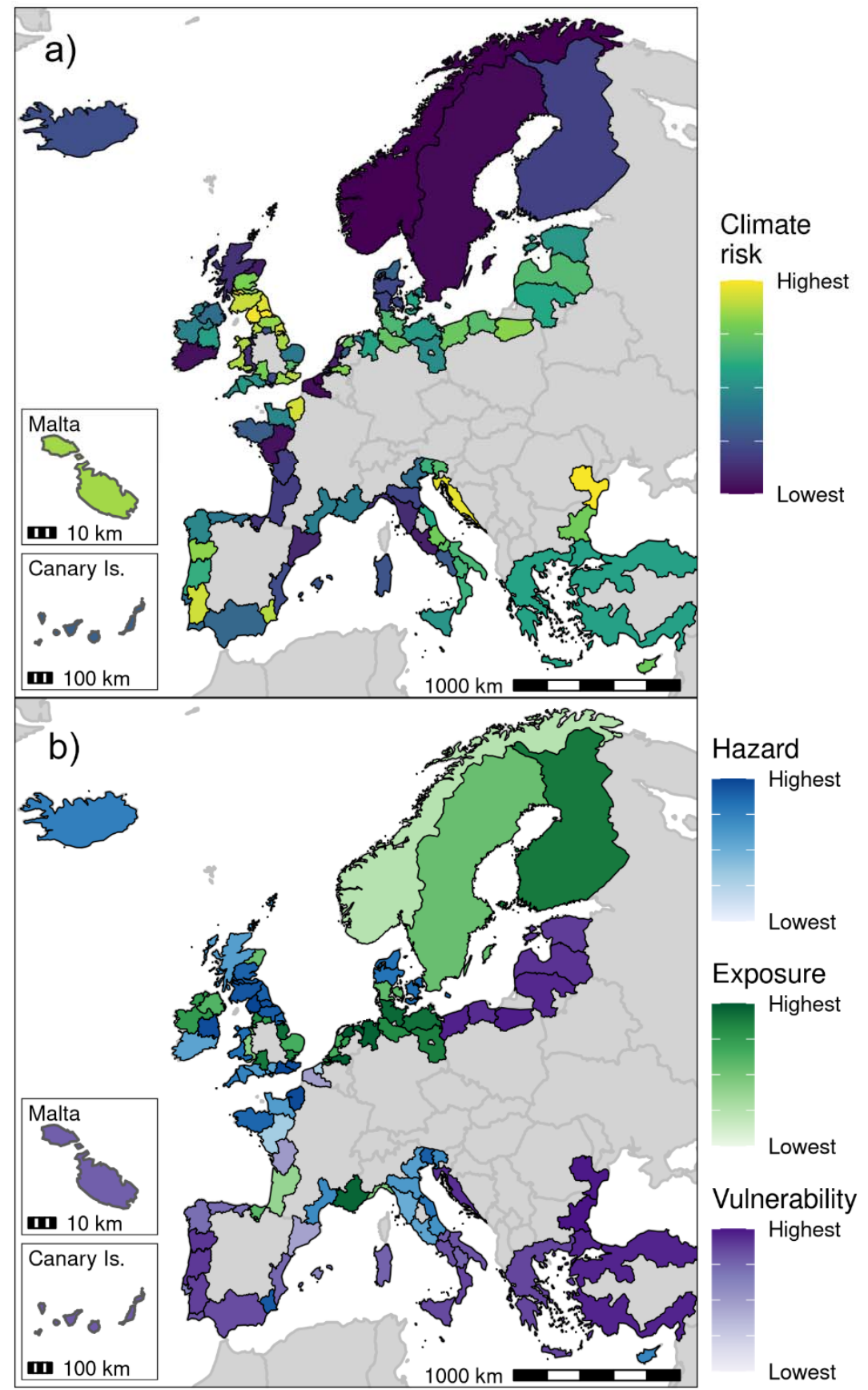

Figure 1 Climate risk of European regions. Maps show a) the combined climate risk ranking for each region and b) the individual component (blue: hazard, green: exposure, purple: vulnerability) making the largest contribution to the combined risk. Colour scales on both panels are linear in the ranking of the corresponding score, but are presented without values, as they have little direct meaning. National borders are also shown for reference. Insets at bottom-left of each panel show small regions. Maps showing the hazard, exposure and vulnerability for each coastal region are included in the supplementary material (Figure S1). 


\section{Fleet Segment Climate Risk Analysis}

150 The risks associated with climate change will also be felt directly by fishing vessels and fleets in addition 151 to regions: we therefore performed a second CRA to examine the climate risk of European fishing fleets. 152 As the basis for this analysis, we followed the EU definition of a "fleet segment" based on the size classes 153 of the vessels, the country of registration, the gear being used and the geographical region being fished 154 (Atlantic or Mediterranean) (STECF, 2018). We integrated climate hazards at the fish population level up 155 to the fleet segment level based on the composition of landings by value of that fleet, while we based 156 exposure on the diversity and dominance of landings and vulnerability on the net profitability of the fleet. 157 Coverage of our analysis at this fleet segment level was less than at the national level: nevertheless, we 158 still covered $75 \%$ or more of total fishery catch value for more than $70 \%$ of the 380 fleet segments within 159 the EU and UK.

160 The smallest class of vessels $(0-6 \mathrm{~m})$ had an appreciably higher climate risk than all other size classes 161 (Figure 2a). For the most part, these fleets operated in the Mediterranean region, particularly in Croatia, 162 Bulgaria, France, Malta and Greece (Table S9). This result reflected, in part, the higher climate risk of 163 stocks in this area, but was also driven by the poor profitability (and therefore higher vulnerability) of 164 these fleets. On the other hand, the high catch diversity of these fleets reduced exposure and helped 165 reduce their net climate risk. 
bioRxiv preprint doi: https://doi.org/10.1101/2020.08.03.234401; this version posted June 29, 2021. The copyright holder for this preprint (which was not certified by peer review) is the author/funder, who has granted bioRxiv a license to display the preprint in perpetuity. It is made available under aCC-BY 4.0 International license.

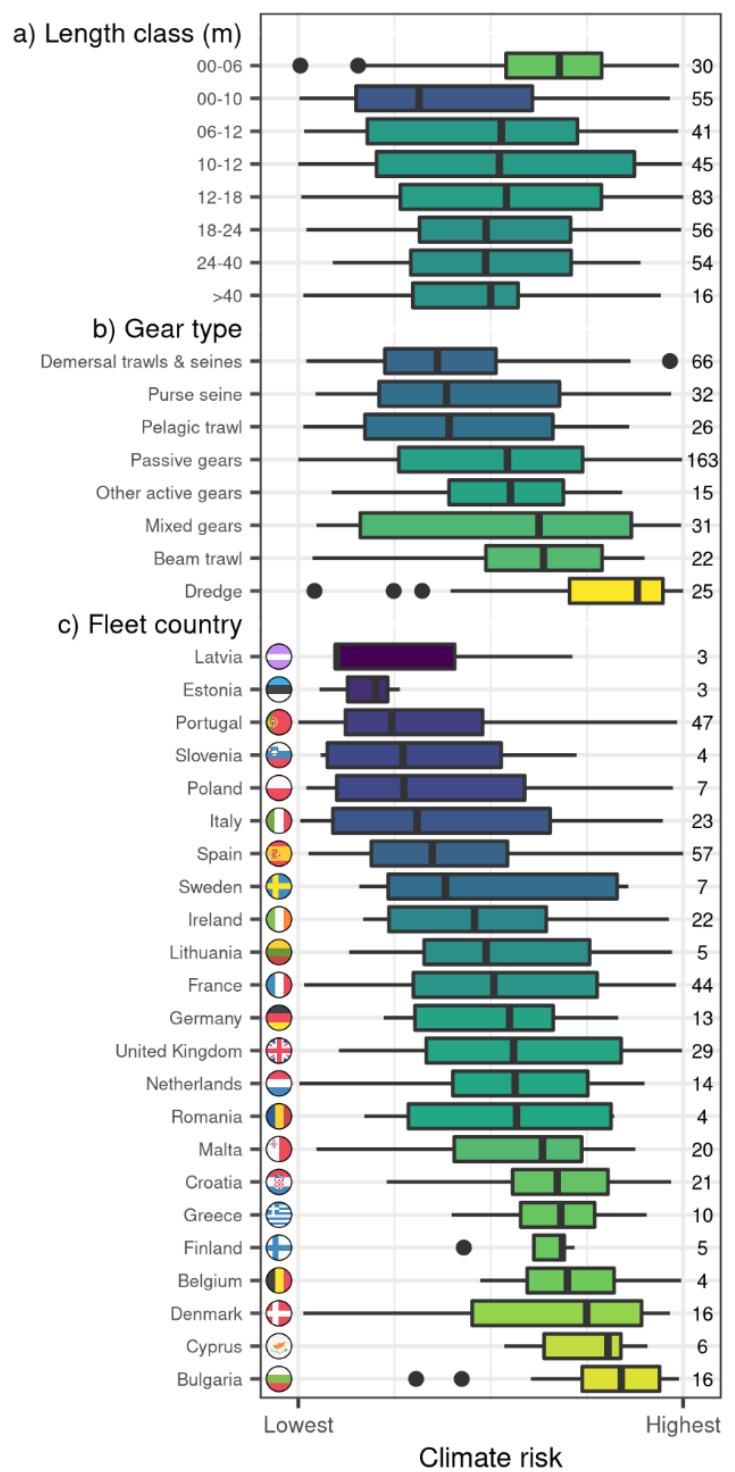

Figure 2 Climate risk of European fleet segments. The climate risk ranking across 380 fleet segments is plotted as a function of a) the size range of the vessels (m), b) the gear type employed (sorted by median risk) and c) the country of origin of the fleet (sorted by median risk). Risk ranking is represented on a linear scale from highest to lowest: the absolute values of risk are not shown, as they have little direct meaning. The distribution of risk is shown as a boxplot, where the vertical line is the median, the box corresponds to the interquartile range (IQR), and the whiskers cover all points less than 1.5 times the IQR from the box. Outliers are plotted as points. Boxes are coloured based on the median climate risk for that category. The number of fleet segments in each class is shown at right. Note that EU definitions of small length classes (less than $12 \mathrm{~m}$ ) vary between individual countries and therefore have a degree of overlap. Specific gear codes are aggregated here to broader-scale categories of "Gear Types" to ensure comparability between Atlantic and Mediterranean fisheries (Table S4). 
Systematic differences in climate risk were also seen among gear types (Figure 2b), where dredgers had the highest climate risk. These fleets generally targeted populations with high climate hazards and had low species diversity in their catches (giving high exposure): good profitability, on the other hand, lowered their vulnerability and somewhat reduced overall risk (Table S9). Fleets using pelagic and demersal trawls together with purse seine fleets had the lowest climate risks, primarily due to the low hazard associated with the species on which they fish.

The strongest differentiation in climate risk between fleet segments was at the national level (Figure 2c). A clear cluster of high climate risk fleet segments could be seen in south-east Europe, particularly in Croatia, Greece, Bulgaria, Cyprus and Romania (Figure S2). The risk profiles underlying each of these cases, however, were quite different, emphasising the need to understand the components in detail. Greek and Cypriot fleets had high climate risks due to poor profitability and, therefore, high vulnerability, while Bulgarian and Romanian fleets active in the Black Sea had extremely low catch diversities, giving them unusually high exposures (Table S9). It is also important to note that there was substantial variation among fleets within a country. For example, two of the five most at-risk fleets (including the most at risk) were Spanish (Table S9), even though the national level median for Spain was amongst the lowest in Europe. A detailed examination of the individual elements of the risk-profile is therefore critical to understanding the underlying factors responsible for these results.

\section{Comparative Analysis}

A strength of the analysis performed here is that the results of the region and fleet CRAs could be directly compared. While the regions and fleets were exposed to the same base set of hazards, the relative importance of each fish or shellfish population (and therefore hazard) differed. Each region and fleet also had its own intrinsic exposure and vulnerability profiles, further modulating the overall climate risk. However, as the base set of hazards was the same in both CRAs, a direct comparison of the two cases was possible, allowing the relative climate risk to coastal-regions and fleets to be gauged.

Systematic differences in risk between fleets and coastal communities were seen among European countries (Figure 3) and several characteristic types of responses were apparent. Countries in southeastern Europe, together with the United Kingdom, had the highest risk across both fleets and coastal regions. The climate risk scores of regions on the south coast of the Baltic Sea (Latvia, Lithuania, Estonia and Poland) were typically higher than their fleet level scores, while the high fleet risk of NW European states was offset by their low risk to regions. Spain and Sweden were characterised by generally low climate risks in both coastal regions and fleets.

Multiple factors act together to determine the individual risk rankings of coastal regions and fleets. In this analysis, the fishing fleets and fishery-dependent regions of any given country were both exposed to the same underlying hazard: climate change impacts on fish populations, primarily shaped by the ecology and biogeography of marine life inhabiting a country's adjacent waters (e.g. Figure S1a). Similarly, substantial variations in biodiversity across European waters constrained the availability of species and therefore impacted the exposure score: for example, high exposure scores characterised states bordering the low-biodiverse Baltic and Black Seas (Figure S1b). Hazard and exposure were also, however, both determined by consumer preference and economic factors that shape the species targeted by fleets and landed in regions. Socio-economic factors also shaped the vulnerability dimension: the relatively high affluence of NW European states, for example, reduced their coastal risk rankings while poorer SE European states received high vulnerability scores (e.g. Figure 3, Figure S1c). Similarly, differences between northern and southern Europe in the size and number of fishing vessels could be clearly expected to influence their profitability, and therefore fleet vulnerability. The processes driving the observed risk- 
bioRxiv preprint doi: https://doi.org/10.1101/2020.08.03.234401; this version posted June 29, 2021. The copyright holder for this preprint (which was not certified by peer review) is the author/funder, who has granted bioRxiv a license to display the preprint in perpetuity. It is made available under aCC-BY 4.0 International license.

222 patterns are therefore complex and reflect the combination of patterns functioning across multiple 223 dimensions at multiple levels. 
bioRxiv preprint doi: https://doi.org/10.1101/2020.08.03.234401; this version posted June 29, 2021. The copyright holder for this preprint (which was not certified by peer review) is the author/funder, who has granted bioRxiv a license to display the preprint in perpetuity. It is made available under aCC-BY 4.0 International license.

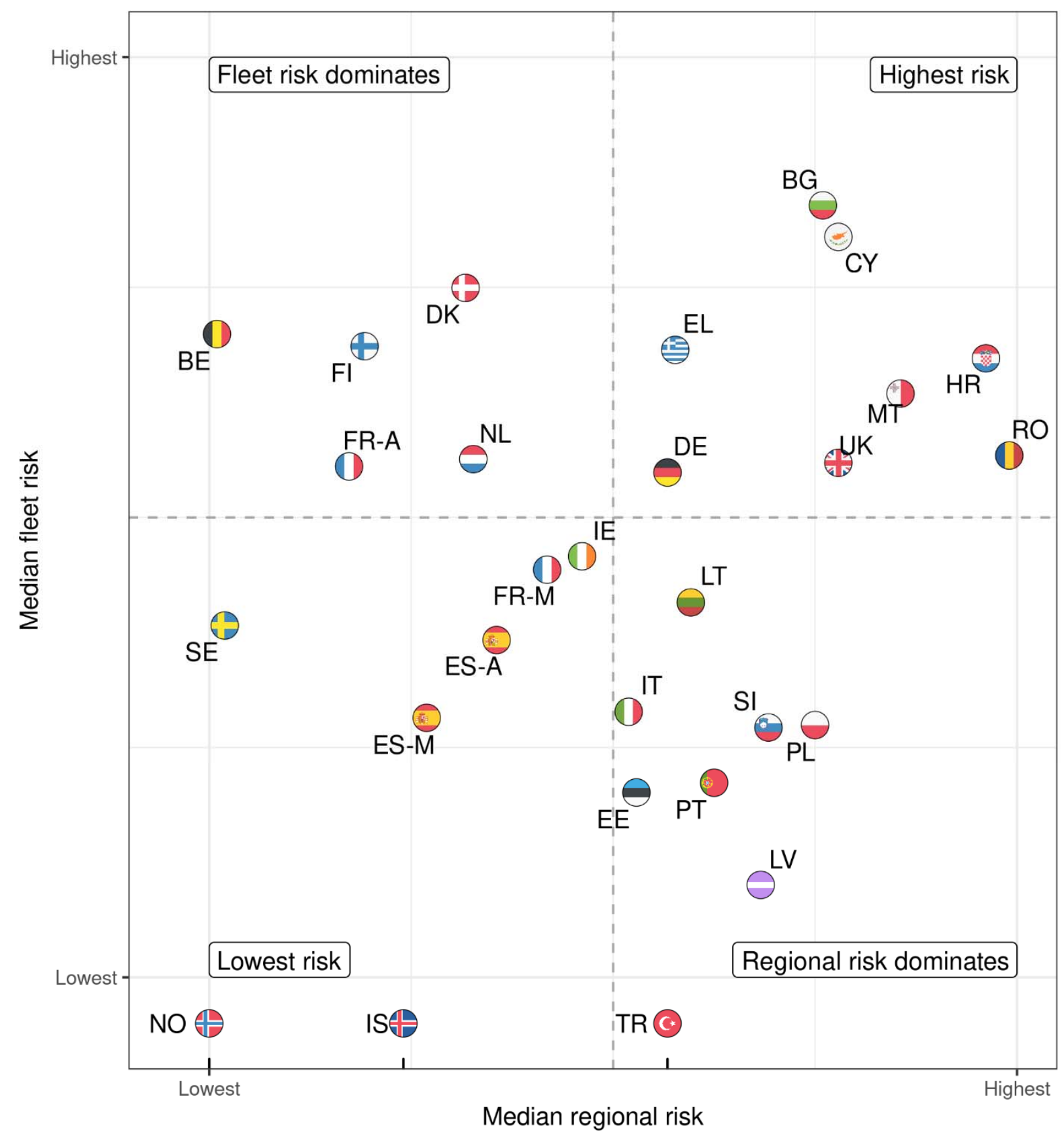

Figure 3 Comparison of the median fleet- and coastal-region risk rankings for European countries. Labels indicate the country code. In addition, France (FR) and Spain (ES) are split into their Atlantic (-A suffix) and Mediterranean (-M suffix) seaboards. As the fleet-segment analysis only covers fleets from the EU and UK, no data are available for Turkey, Norway and Iceland: their regional risk results are plotted in the horizontal margin. Dashed lines divide the coordinate system into quarters. Country codes: BE: Belgium. BG: Bulgaria. CY: Cyprus. DE: Germany. DK: Denmark. EE: Estonia. EL: Greece. ES: Spain. FI: Finland. FR: France. HR: Croatia. IE: Ireland. IS: Iceland. IT: Italy. LT: Lithuania. LV: Latvia. MT: Malta. NL: Netherlands. NO: Norway. PL: Poland. PT: Portugal. RO: Romania. SE: Sweden. SI: Slovenia. TR: Turkey. UK: United Kingdom. 


\section{Discussion and Conclusions}

235 Our analysis highlights the wide variety of challenges facing European countries in adapting their

236 fisheries sectors to a changing climate. In some cases, such as in the southern-Baltic states, a focus on 237 building adaptive capacity in coastal regions would be of most benefit e.g. by creating alternative 238 employment opportunities or providing an economic 'safety net' through wider social measures. In other regions, fleet risks dominate and therefore increasing the efficiency, adaptive capacity and catch diversity of the fleets would appear to be a priority. Some areas, such as the UK and south-east Europe appear to require both types of intervention and therefore present the greatest adaptation challenges. It is clear that no "one-size-fits-all" solution that can be applied across all European waters or even, in some cases, across a country (e.g. the UK): climate adaptation plans, therefore, need to be tailored to these local realities.

Climate risk and vulnerability analyses can play a key role in shaping these adaptation plans. By increasing awareness of the elements that contribute most to a fleet or coastal region's risk (Allison et al., 2009), CVAs and CRAs can help maximise the effectiveness of interventions given limited resources (Lindegren and Brander, 2018). Previous socio-economic linked analyses have focused on adaptive capacity (in the CVA framework) as a focal point for action (Allison et al., 2009; Cinner et al., 2013). However, the diversity of European risk profiles found here also highlights the need for adaptation actions across all components contributing to climate risk.

252 Ensuring sustainable management of the living marine resources upon which the sector rests is a key 253 action for the European fisheries sector. The impacts of over-exploitation can be more important than those stemming from climate change, particularly in the heavily fished North Atlantic region (Cheung et al., 2018). Maintaining stocks at a higher abundance leads to increases in genetic diversity, metapopulation complexity, and age structure, all of which make stocks more resilient to the challenges of a changing environment (Drinkwater et al., 2010; Planque et al., 2010). The ensuing increase in productivity and incomes also simultaneously benefits both fishing fleets and regions, generating a "winwin" effect (Bell et al., 2013). Fisheries scientists already have many of the tools necessary to ensure that management systems are robust to climate change and climate variability (Pinsky and Mantua, 2014), while new tools, such as seasonal-to-decadal marine ecological forecasts and early-warning systems (Payne et al., 2017), can potentially provide the basis for additional coping strategies (Hobday et al., 263 2018).

264 Diversification is a second key action to reduce climate risk. Fishing fleets and coastal regions relying on only a few species have an elevated risk of climate impacts: increasing this spread reduces (by definition) exposure and buffers fleets and regions against climate risk (Cline et al., 2017; Young et al., 2019; Pinsky et al., 2020). Diversification of catches and landings can take place autonomously as fishers respond to changes in the abundance and distribution of the fish they catch (Pinsky and Mantua, 2014; Lindegren and Brander, 2018). For example, changes in the distribution of fish species in waters surrounding the UK (Perry, 2005; Simpson et al., 2011; Baudron et al., 2020) have led to the development of new fisheries for squid, seabass and red mullet, amongst others (Pinnegar et al., 2020). CRAs such as the one presented here can also have an important role in this process by highlighting alternative species or populations with a lower climate hazard that can be targeted, thereby further reducing risk. Alternatively, reducing fisheries dependency and diversifying income sources by, for example, participating in multiple fisheries or in 
There are, however, barriers to diversification (Cline et al., 2017; Young et al., 2019), including knowledge, economic and governance barriers. For example, the ability to catch new species may be limited by existing quota agreements (Pinsky et al., 2018) such as the EU Common Fisheries Policy "relative stability" clauses, whereby the allocation of fishing quotas is fixed to reflect historical catches from 1973-1978 (Hoefnagel et al., 2015). Ecology can also be constraining: the limited catch diversity and therefore high exposure of fleets and coastal regions adjoining the Black and Baltic Seas, for example, arises at least in part from the naturally low biodiversity of these seas. Changing target species or fishing technologies can also be costly, creating financial barriers to diversification (Kasperski and Holland, 2013).

286

287

288

289

290

291

292

293

294

295

Governance also has a key role to play in coordinating and driving actions to reduce the vulnerability of fleets and regions. Investments and support for developing new, and switching between existing, fishing, storage, transport and processing technologies can increase the efficiency of fleet operations and therefore reduce vulnerability (McIlgorm et al., 2010; Bell et al., 2011; Pinsky and Mantua, 2014). Increasing regional development, including employment opportunities outside the fisheries sector, reduces regional vulnerability and risk (Allison et al., 2009; Badjeck et al., 2010). Furthermore, both fishing fleets and coastal regions can also potentially benefit from governance-led actions that increase the flexibility, ability to learn, social organisation and the power and freedom to respond to challenges (Cinner et al., 2018). Regional, national and European governments therefore have a critical role to play in helping fisheries and ocean-dependent regions to adapt to the risks presented by climate change.

Several key caveats of our analysis need to be highlighted. Our analysis focused solely on the sensitivity to ocean warming, ignoring other climate-driven processes, such as ocean acidification, deoxygenation, and changes in storminess or circulation patterns (IPCC, 2019; Pinnegar et al., 2019) that, while important, we view as second order effects. Spatial differences in the rates of warming across European regional seas were also not accounted for here but the range of these rates (up to $2^{\circ} \mathrm{C}$ by 2050) is much smaller compared to the variability in thermal safety margins across the range of some species (range up to $15^{\circ} \mathrm{C}$ ) (Figure S4). We were unable to find European-wide data sources that quantify the relative importance of fisheries in each of our coastal regions (e.g. Natale et al., 2013): filling this data gap would further refine the analysis. The treatment of uncertainty in CVAs and CRAs varies greatly between studies (Hare et al., 2016; Spencer et al., 2019) but in such a semi-quantitative analysis, the choice of metrics is usually the most important aspect (Monnereau et al., 2017). We believe that this "structural uncertainty" (sensu Payne et al., 2016) is best addressed by focusing on a limited but transparent and readily interpretable set of indicators, rather than by quantifying uncertainties or increasing complexity. Finally, while we have considered European fisheries targeting fish stocks that span the Mediterranean Sea, we have not incorporated coastal communities in African countries that also fish on these same stocks. The relatively low GDP per capita of these communities suggests that they would have correspondingly high regional vulnerabilities and, therefore, correspondingly high climate risk profiles but it is not possible to draw robust conclusions in the absence of appropriate data sets. Nevertheless, the population-level hazards generated here (Table S7) could be readily applied to aid such analyses in the future.

The limitations of the CRA approach itself also need to be borne in mind. Here, we explicitly focus on the "negative" impacts of a warming climate, following the IPCC framing of climate hazard in terms of "adverse effects" (Oppenheimer et al., 2014; IPCC, 2019), even though there will also undoubtedly be some "positive" effects (eg Kjesbu et al., 2014) that may partially offset the negative effects at some localities. However, estimating a "net" hazard requires quantifying changes and placing them on a common basis (e.g. economic impacts), a challenging task best done in explicitly quantitative settings such as end-to-end models rather than CRAs. Similarly, CRAs are not intended to make quantitative 
"predictions" of the future (Pecl et al., 2014) and we are not aware of cases where they have been used in this manner. Rather, the strength of the CRA approach is its ability to provide a transparent and consistent framework for the rapid assessment of climate risk across a (very) wide range of fleets and coastal regions, allowing the most at-risk elements to be identified and prioritised for adaptation actions (Pinnegar et al., 2019). Developing climate adaptation plans for local situations should involve detailed quantitative modelling to provide the necessary details.

This study has shown that, even though the average climate risk to European countries is moderate compared to many other countries across the globe (Allison et al., 2009; Blasiak et al., 2017), major differences exist across the European continent. This corroborates with fine-scale spatial differences among fishing communities documented in eastern North America (Colburn et al., 2016; Rogers et al., 2019) and the Caribbean (Monnereau et al., 2015; Pinnegar et al., 2019), where individual communities would be best served by different adaptation actions. Our detailed analyses allow a distinction between climate hazard, exposure and vulnerability as key sources of climate risk to fleets and coastal regions and highlight where (and what) adaptation measures can have the greatest impact in increasing resilience, given limited financial resources.

\section{Acknowledgements}

This project received funding from the European Union's Horizon 2020 research and innovation programme under grant agreement No 678193 (CERES - Climate change and European Aquatic Resources). The results generated by this analysis can be explored using an online tool available at https://markpayne.shinyapps.io/CERES_climate_risk/ Source code is available at https://github.com/markpayneatwork/CERES_vulnerability. "Fishing Boat", "Urban" and "Thermometer" icons in Figure 4 by smallikeart from www.flaticon.com.

\section{Methods}

\section{General approach}

We have applied an integrated approach to a climate risk assessment (CRA) across the European fisheries sector. The CRA has three major components (Figure 4; Figure S3). The first and most fundamental of these is the population hazard component, where the hazard associated with adverse climate change impacts on individual fish populations is quantified. We then use these hazard metrics as inputs into two parallel climate risk assessments focussing on coastal regions and fishing fleets in turn. In each of these cases, the population hazard is integrated up to the region or fleet level based on information about the relative importance of each fish population to that unit to form the region- or fleet-specific hazards. These hazard data are then complemented with region- and fleet-focused exposure and vulnerability metrics to produce a climate risk for each. Finally, we combine the risks from each component into a comparative analysis across nations. 
bioRxiv preprint doi: https://doi.org/10.1101/2020.08.03.234401; this version posted June 29, 2021. The copyright holder for this preprint (which was not certified by peer review) is the author/funder, who has granted bioRxiv a license to display the preprint in perpetuity. It is made available under aCC-BY 4.0 International license.

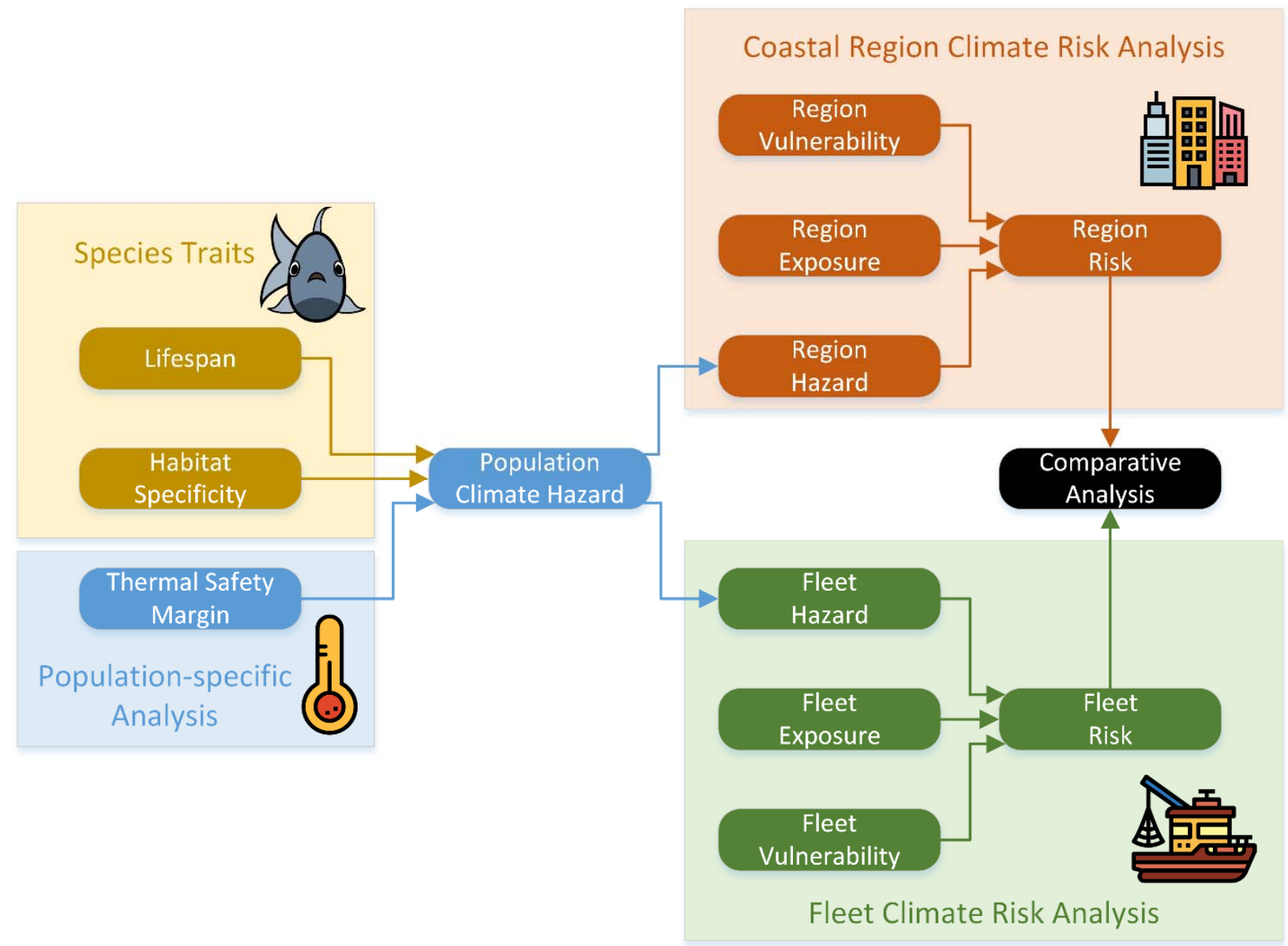

Figure 4 Schematic diagram illustrating the approach used here to estimate climate risk in European fishery-dependent coastal regions and fishing fleets. Species traits and population specific analyses of the thermal safety margin are combined to give a population-specific climate hazard. This hazard then forms the basis for the region and fleet level CRAs, based on the combination of hazard, exposure and vulnerability. Finally, the region and fleet risks are combined again into a comparative analysis. A detailed flow diagram is presented in the supplementary material (Figure S3). 


\section{Scope and Data Sources}

367 We aimed to assess the climate risk for the European marine fisheries sector, including all 22 EU

368 countries with marine borders, the United Kingdom, Norway, Iceland and Turkey. We based our analysis 369 primarily on catch data from FAO Areas 21, 27, 34 and 37 held in the EUROSTAT database (Table S1), excluding distant water fleets. While this database covers more than 1200 species, many of these are economically minor. We therefore simplified our task by focussing on species making up the largest $90 \%$ of the value of the marine fish and shellfish sector in each country and across Europe as a whole. Two species predominately inhabiting freshwater, European perch (Perca fluviatilis) and pike-perch (Sander lucioperca), were removed from the database. Misspelled (or alternative) scientific names were corrected where we could identify these (following World Register of Marine Species, WoRMS) (Table S3).

Regional analyses were performed for European coastal regions based on NUTS2 statistical units. Subnational indicators of landings composition were derived from monthly harbour-level "first-sales" data from the EU Market Observatory for Fisheries and Aquaculture (EUMOFA) (Table S1). In cases where this data covered more than one NUTS2 unit within a country (10 countries), the harbour data was aggregated up to NUTS2 units based on the geographical coordinates of the harbours. Where EUMOFA data coverage was insufficient, the coastal NUTS2 units of that country were merged into one "region" (Table S5) and EUROSTAT national landings data were assigned to it (Table S1). Socio-economic data for the NUTS2 units was also obtained from EUROSTAT and integrated up to our "regions", if relevant.

The Annual Economic Report (AER) provided by the EU Scientific, Technical and Economic Committee for Fisheries (STECF) (STECF, 2018) formed the basis of the fishing fleet analysis (Table S1). This dataset has the advantage of providing a single coherent source for fleet segments (the combination of fishing technique and a vessel length category) across all of the European Union and United Kingdom: however, it does not include data on fleets from Norway, Iceland or Turkey, and in the absence of comparable datasets, these countries were not included in this part of the analysis.

390 All data were averaged over the period 2010-2018, where available.

\section{Hazard Metrics}

The hazard dimension of our CRA measures the strength and severity of adverse climate change impacts on the unit of interest: in this case, fish populations in European waters. Many previous CVAs and CRAs do not distinguish between the positive and negative effects of climate change, and simply highlight elements of their study system that will change, making interpretation difficult. In contrast, and following the IPCC's definition of risk in relation to an "adverse event" (IPCC, 2019), we focus explicitly on "negative" impacts in order to have an unambiguous interpretation.

398 We consider the hazard due to climate change impacts on living marine resources as being the combination of both species-specific and population-specific processes as follows:

\section{Species-specific processes}

401 A trait-based approach was employed to characterise the hazard of climate change to a species. Such an 402 approach is well established in climate risk and vulnerability analyses (Pecl et al., 2014; Hare et al., 2016; 403 Jones and Cheung, 2018), due to its ability to draw on general understanding of the response of species to 404 climate change. Trait data was collated from previously published databases (Engelhard et al., 2011; 405 Pecuchet et al., 2017; Beukhof et al., 2019b, 2019a) and complemented with data from Fishbase (Froese 406 and Pauly, 2019) and Sealifebase (Palomares and Pauly, 2019) (accessed April-July 2019) (Table S1). Of 407 the original set of species from EUROSTAT, 24 taxa were only at the genus level, and appropriate trait 
sets were therefore identified based on 'exemplar species': in some cases different exemplar species were used for the North Atlantic (FAO Area 27) and Mediterranean regions (FAO Area 37) (Table S2). Barnacles (Pollicipes pollicipes) and solen razor clams (Solen spp.) were removed from the analysis owing to a lack of comparable biological trait data and difficulties identifying suitable exemplar species.

Trait selection aimed to avoid double-counting information due to inclusion of correlated traits, a commonly overlooked issue (Pecuchet et al., 2017) that impacts many published analyses (Cheung et al., 2005, 2018; Hare et al., 2016; Jones and Cheung, 2018). For example, smaller fish are typically planktivorous, live shorter and grow faster, giving a high correlation between maximum length, lifespan, growth rates and trophic level. Lifespan is the most commonly available of these metrics and was therefore chosen as an exemplar for this set of traits. Shorter lifespans are associated with seasonal and variable environments (Pecuchet et al., 2017), implying robustness to change and variability, paralleling the approach used in other studies (Cheung et al., 2005, 2018; Hare et al., 2016; Jones and Cheung, 2018).

A "habitat specificity" metric was also developed. Species with spatially restricted habitat requirements during part or all of their life-history are recognised as being more sensitive to disruption (Rijnsdorp et al., 2009; Petitgas et al., 2013). In addition, mobile species have the ability to move rapidly to avoid unfavourable conditions in a way that sedentary species do not, and therefore have a lower climate hazard (Pinnegar et al., 2019). Traits defining the mobility and vertical and horizontal habitats were therefore collated into a single "habitat-specificity score" (Table 2). The final set of traits is included as supplementary material (Table S6).

Table 2 Combination of mobility, vertical and horizontal habitat traits to generate a habitat specificity score. Trait categories follow the scheme of Engelhard et al (Engelhard et al., 2011).

\begin{tabular}{|c|c|c|c|}
\hline Habitat Specificity & Mobility & Vertical habitat & Horizontal habitat \\
\hline \multirow[t]{3}{*}{ Low $(0.00)$} & Highly migratory species & Any & Any \\
\hline & Mobile & Any & Oceanic \\
\hline & Mobile & $\begin{array}{l}\text { Bathydemersal } \\
\text { Mesopelagic }\end{array}$ & Slope \\
\hline \multirow[t]{3}{*}{ Medium $(0.33)$} & $\begin{array}{l}\text { Mobile } \\
\text { Unknown }\end{array}$ & $\begin{array}{l}\text { Benthopelagic } \\
\text { Demersal } \\
\text { Pelagic } \\
\text { Epipelagic }\end{array}$ & $\begin{array}{l}\text { Slope } \\
\text { Shelf } \\
\text { Outer shelf }\end{array}$ \\
\hline & Unknown & Bathydemersal & Slope \\
\hline & Mobile & Bathydemersal & Outer shelf \\
\hline \multirow[t]{3}{*}{ High (0.67) } & $\begin{array}{l}\text { Mobile } \\
\text { (catadromous/anadromous) }\end{array}$ & Pelagic & Any \\
\hline & Mobile & Demersal & Inner shelf \\
\hline & Mobile & Benthopelagic & Coastal \\
\hline \multirow[t]{2}{*}{ Very high (1.00) } & Sedentary & Any & Any \\
\hline & Mobile & Reef-associated & Any \\
\hline
\end{tabular}

432 The stress a fish population experiences as the ocean warms depends on the amount of warming, a commonly employed metric of exposure in CVAs (Allison et al., 2009; Hare et al., 2016). However, the 
physiological context of this warming is also critical but often overlooked. For example, cod (Gadus morhua) in the North Sea are close to their upper thermal limit, and will therefore experience negative impacts of warming, while cod in the Barents Sea are far from this limit and will experience little or no negative effects of the same amount of warming (Drinkwater, 2005). Such a spatial and physiological context of warming, often overlooked in many CRAs and CVAs, is critical to differentiate the climate hazard among different populations of the same species.

We resolve this problem in two ways. First, we perform our analysis at the "population" level, defined as the combination of species and FAO subarea e.g., cod in subarea 27.4 (North Sea). Note that while this approach is similar to that used to manage many European fish stocks, we explicitly avoid the use of the term "stock" to refer to this unit of analysis, as it has clear implications in fisheries management but is not always the same as our definition "population". Populations comprising less than $5 \%$ of the total catch of the species were excluded from the analysis. Secondly, we place the degree of warming experienced by these populations in a physiological context using estimates of the thermal-safety margin (TSM) (Deutsch et al., 2008; Sunday et al., 2014; Pinsky et al., 2019; Dahlke et al., 2020). The TSM is estimated as the difference between the empirically-derived maximum temperature that the species prefers and the temperature of the environment: high TSMs indicate a high capacity to tolerate warming. Populationspecific TSMs therefore permit a fine-grained measure of the warming-related hazard.

We derived population-specific estimates of TSM from the habitat models, parameters and maps provided by Aquamaps www.aquamaps.org (Kesner-Reyes et al., 2012) (Table S1). We downloaded "native distribution maps" from the Aquamaps website for the species included in our analysis: where multiple maps were available, choice was guided by Aquamaps' internal quality ranking system. For the invasive species veined rapa whelk (Rapana venosa), originally from waters around Japan, Korea and China but now supporting a large fishery in the Black Sea, the "Suitable Habitat map" was used. From each species' map we used the " $90^{\text {th }}$ percentile" parameter for the temperature response as an empirical estimate of its upper thermal tolerance. Temperatures in a subarea were based on the data underpinning the Aquamaps model (NOAA NCEP Climatology, 1982-1999) (Kesner-Reyes et al., 2012), ensuring congruence between the tolerance parameters and the temperature data. Sea-surface or -bottom temperature data, as used in generating the species' Aquamap, were masked using the habitat model to eliminate unsuitable habitat for each individual species (Figure 5). Projected temperatures changes from 1999 to 2050 under the SRES A2 scenario were also available in this dataset and extracted for each population in the same manner for use in supporting analyses (Figure S4). Population-specific estimates of TSM were calculated as the median difference between the species' " $90^{\text {th }}$ percentile" parameter and temperature across all valid pixels in that subarea. 


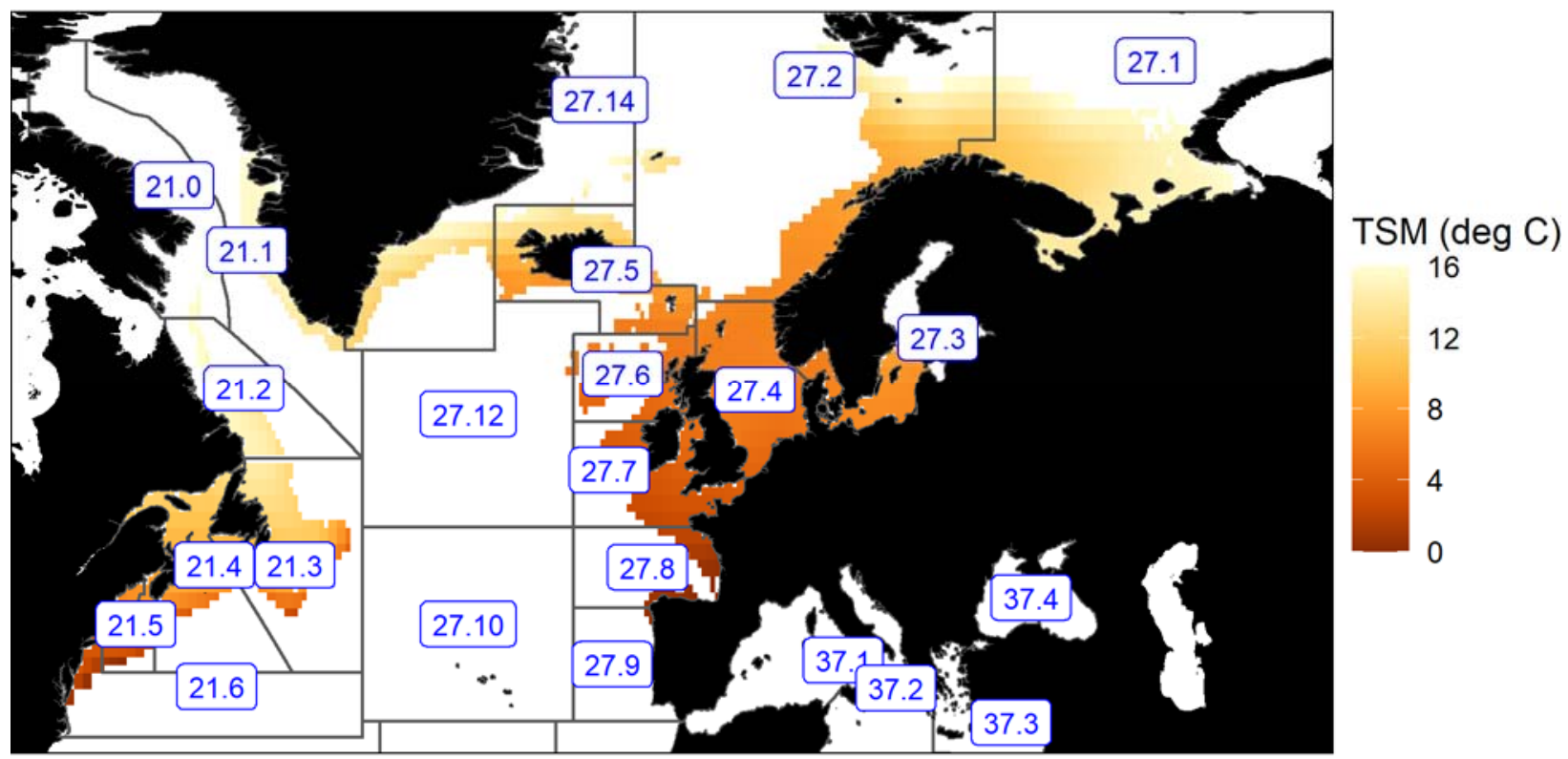

Figure 5 Use of Aquamaps to calculate TSM metrics. Atlantic cod (Gadus morhua) as an example. Environmental data and species thermal tolerance data from Aquamaps are used to estimate the thermal safety margin (TSM) for this species (coloured pixels) and masked using the habitat model to limit data to modelled regions of occurrence. Median TSM values are then calculated within each FAO subarea defining a population (grey polygons, blue labels). 


\section{Population-level hazard}

475 Hazard metrics were combined based on their relative ranking for each population. We chose to give equal weight to the species (lifespan, habitat-specificity) and population-level (TSM) aspects of the analysis when combining the metrics: after converting to a rank percentile, a weight of 0.25 was given to the species' lifespan (shorter-lifespans give a low hazard), 0.25 for the species' habitat-specificity (low specificity gives a low hazard) and 0.5 to the population TSM (high TSMs give a low hazard). Equal weighting of the metrics $(0.33$ / 0.33 / 0.33) was also considered (Hamilton and Ferry, 2018) but the resulting hazard metrics were found to be strongly correlated with the original $(0.25 / 0.25 / 0.50)$ weighting (Spearman correlation coefficient of 0.95; Figure S5), indicating that the relative hazard ranking of individual populations under the two schemes is very similar.

484 Population-level hazard scores were integrated up to coastal region and fishing-fleet levels. In the case of 485 the fleet analysis, this was based on the relative composition (by value) of the populations that each fleet 486 fishes on, while in the case of the coastal region analysis it was based on the composition (by value) of 487 landings in that region (Figure 4, Figure S3).

\section{Exposure metrics}

489 We define exposure as an indicator of how sensitive a coastal region or fishing fleet is to changes in the 490 fish populations it is dependent on. Fleets or coastal regions have lower exposure if they catch a wide range of different fish species, rather than concentrating on a specific resource (Cline et al., 2017; Pinnegar et al., 2019; Young et al., 2019). If one species is reduced or lost due to the effects of climate change, the impact of that loss is relatively less severe for fleets and coastal regions that are dependent on a broad portfolio of species. We therefore defined our exposure metrics following this logic, using two different metrics to characterise diversity of catch or landings: i) the Shannon diversity index, one of the most commonly used diversity indices in ecology and ii) Simpson's dominance index, a statistic that emphasizes the relative abundance of the most common species in the sample (Pinnegar et al., 2019).

498 For coastal regions, exposure metrics were based on the value of landings data from EUMOFA and EUROSTAT (Table S1; Figure S3). While EUROSTAT data is species resolved, EUMOFA data is organised in approximately 100 "main commercial species" (MCS) groupings: we therefore harmonised the two datasets by aggregating EUROSTAT data to the MCS groupings based on correlation keys provided by EUMOFA. The Shannon and Simpson metrics were then calculated to estimate the diversity

503 of MCS groups.

504 For fleet segments, the value of landings is available by species code from the STECF Annual Economic 505 Report (STECF, 2018). The two diversity indices could therefore be calculated directly to quantify the 506 diversity of species caught.

507 In both cases, the exposure index was produced as a composite index of the two indices described above 508 by averaging the percentile ranks and then re-calculating percentile ranks again.

\section{Vulnerability metrics}

510 Vulnerability in this setting refers to the ability of the analysis unit (either a coastal region or a fleet) to 511 effectively address the hazard via adaptation or coping strategies.

512 The regional vulnerability metric was based on the gross-domestic product per capita of the region, as 513 calculated from EUROSTAT data at the NUTS2 level (Table S1). Regions with high GDP per capita 
were viewed as having a high adaptive capacity and therefore low vulnerability. Regional vulnerability was calculated as the percentile rank of this statistic.

Fleet segment vulnerability was based on the net profit margin (NPM). This is a standard economic metric, defined as net profit (i.e. revenue minus variable, fixed and opportunity costs) divided by the total revenue: it therefore represents how much of the total income generated by the fleet is net profit (STECF, 2018). NPM takes into account many of the different factors that influence the profitability of the fleet, and is also scale independent (as profitability is divided by the revenue), allowing comparison of both large and small segments. NPM was calculated for each fleet segment based on economic data from the STECF Annual Economic Report (STECF, 2018) (Table S1), and the vulnerability score generated based on percentile rank. Fleet segments with high profitability were viewed as being less vulnerable to the effects of climate change, as they could absorb the potential loss associated with a climate change having a negative impact on their target species.

\section{Climate risk metrics}

For each of the coastal regions, and for each of the fleet segments, the overall climate risk was calculated as the unweighted mean of the hazard, exposure and vulnerability percentile ranks.

\section{References}

Adger, N. W. 1999. Social Vulnerability to Climate Change and Extremes in Coastal Vietnam. World Development, 27: 249-269. Pergamon.

Allison, E. H., Perry, A. L., Badjeck, M.-C., Neil Adger, W., Brown, K., Conway, D., Halls, A. S., et al. 2009. Vulnerability of national economies to the impacts of climate change on fisheries. Fish and Fisheries, 10: 173-196.

Badjeck, M. C., Allison, E. H., Halls, A. S., and Dulvy, N. K. 2010. Impacts of climate variability and change on fishery-based livelihoods. Marine Policy, 34: 375-383. Pergamon.

Barange, M., Merino, G., Blanchard, J. L., Scholtens, J., Harle, J., Allison, E. H., Allen, J. I., et al. 2014. Impacts of climate change on marine ecosystem production in societies dependent on fisheries. Nature Climate Change, 4: 211-216.

Barsley, W., De Young, C., and Brugere, C. 2013. Vulnerability assessment methodologies: an annotated bibliography for climate change and the fisheries and aquaculture sector. FAO Fisheries and Aquaculture Circular No. 1083.

Baudron, A. R., Brunel, T., Blanchet, M. A., Hidalgo, M., Chust, G., Brown, E. J., Kleisner, K. M., et al. 2020. Changing fish distributions challenge the effective management of European fisheries. Ecography, 43: 494-505.

Bell, J. D., Johnson, J. E., and Hobday, A. J. 2011. Vulnerability of tropical pacific fisheries and aquaculture to climate change. Secretariat of the Pacific Community. 925 pp.

Bell, J. D., Reid, C., Batty, M. J., Lehodey, P., Rodwell, L., Hobday, A. J., Johnson, J. E., et al. 2013. Effects of climate change on oceanic fisheries in the tropical Pacific: implications for economic development and food security. Climatic Change, 119: 199-212.

Beukhof, E., Dencker, T. S., Palomares, M. L. D., and Maureaud, A. 2019a. A trait collection of marine fish species from North Atlantic and Northeast Pacific continental shelf seas. Pangaea: 1-12.

Beukhof, E., Frelat, R., Pecuchet, L., Maureaud, A., Dencker, T. S., Sólmundsson, J., Punzón, A., et al. 2019b. Marine fish traits follow fast-slow continuum across oceans. Scientific reports, 9: 17878. 
NLM (Medline).

556

557

558

559

560

561

562

563

564

565

566

567

568

569

570

571

572

573

574

575

576

577

578

579

580

581

582

583

584

585

586

587

588

589

590

591

592

593

594

595

596

597

598

Blasiak, R., Spijkers, J., Tokunaga, K., Pittman, J., Yagi, N., and Österblom, H. 2017. Climate change and marine fisheries: Least developed countries top global index of vulnerability. PLOS ONE, 12: e0179632.

Brugere, C., and De Young, C. 2015. Assessing climate change vulnerability in fisheries and aquaculture Available methodologies and their relevance for the sector. FAO Fisheries and Aquaculture Technical Paper 597. FAO, Rome.

Cardona, O. D., Van Aalst, M. K., Birkmann, J., Fordham, M., Mc Gregor, G., Rosa, P., Pulwarty, R. S., et al. 2012. Determinants of risk: Exposure and vulnerability. In Managing the Risks of Extreme Events and Disasters to Advance Climate Change Adaptation: A Special Report of Working Groups I and II of the Intergovernmental Panel on Climate Change (IPCC)., pp. 65-108. Ed. by C. B. Field, V. Barros, T. F. Stocker, D. Qin, D. J. Dokken, K. L. Ebi, M. D. Mastrandrea, et al. Cambridge University Press, Cambridge, UK, and New York, NY, US.

Cheung, W. W. L., Pitcher, T. J., and Pauly, D. 2005. A fuzzy logic expert system to estimate intrinsic extinction vulnerabilities of marine fishes to fishing. Biological Conservation, 124: 97-111.

Cheung, W. W. L., Jones, M. C., Reygondeau, G., and Frölicher, T. L. 2018. Opportunities for climate-risk reduction through effective fisheries management. Global Change Biology, 24: 5149-5163.

Cinner, J. E., Huchery, C., Darling, E. S., Humphries, A. T., Graham, N. A. J., Hicks, C. C., Marshall, N., et al. 2013. Evaluating Social and Ecological Vulnerability of Coral Reef Fisheries to Climate Change. PLoS ONE, 8: e74321. Public Library of Science.

Cinner, J. E., Adger, W. N., Allison, E. H., Barnes, M. L., Brown, K., Cohen, P. J., Gelcich, S., et al. 2018. Building adaptive capacity to climate change in tropical coastal communities. Nature Climate Change, 8: 117-123. Springer US.

Cline, T. J., Schindler, D. E., and Hilborn, R. 2017. Fisheries portfolio diversification and turnover buffer Alaskan fishing communities from abrupt resource and market changes. Nature Communications, 8 : 1-7. Nature Publishing Group.

Colburn, L. L., Jepson, M., Weng, C., Seara, T., Weiss, J., and Hare, J. A. 2016. Indicators of climate change and social vulnerability in fishing dependent communities along the Eastern and Gulf Coasts of the United States. Marine Policy, 74: 323-333. Elsevier.

Connelly, A., Carter, J., Handley, J., and Hincks, S. 2018. Enhancing the practical utility of risk assessments in climate change adaptation. Sustainability (Switzerland), 10: 1-12.

Dahlke, F. T., Wohlrab, S., Butzin, M., and Pörtner, H.-O. 2020. Thermal bottlenecks in the life cycle define climate vulnerability of fish. Science, 369: 65-70. American Association for the Advancement of Science.

Deutsch, C. A., Tewksbury, J. J., Huey, R. B., Sheldon, K. S., Ghalambor, C. K., Haak, D. C., and Martin, P. R. 2008. Impacts of climate warming on terrestrial ectotherms across latitude. Proceedings of the National Academy of Sciences, 105: 6668-6672.

Drinkwater, K. F. 2005. The response of Atlantic cod (Gadus morhua) to future climate change. ICES Journal of Marine Science, 62: 1327-1337.

Drinkwater, K. F., Beaugrand, G., Kaeriyama, M., Kim, S., Ottersen, G., Perry, R. I., Pörtner, H.-O., et al. 2010. On the processes linking climate to ecosystem changes. Journal of Marine Systems, 79: 374388.

Ekstrom, J. A., Suatoni, L., Cooley, S. R., Pendleton, L. H., Waldbusser, G. G., Cinner, J. E., Ritter, J., et al. 2015. Vulnerability and adaptation of US shellfisheries to ocean acidification. Nature Climate 
600

601

602

603

604

605

606

607

608

609

610

611

612

613

614

615

616

617

618

619

620

621

622

623

624

625

626

627

628

629

630

631

632

633

634

635

636

637

638

639

640
Engelhard, G. H., Ellis, J. R., Payne, M. R., ter Hofstede, R., and Pinnegar, J. K. 2011. Ecotypes as a concept for exploring responses to climate change in fish assemblages. ICES Journal of Marine Science, 68: 580-591.

FAO. 2018. Impacts of climate change on fisheries and aquaculture. $654 \mathrm{pp}$.

FAO. 2020. The State of World Fisheries and Aquaculture 2020. FAO.

Froese, R., and Pauly, D. 2019. Fishbase. www.fishbase.org.

Fulton, E. A., Hobday, A. J., Pethybridge, H., Blanchard, J., Bulman, C., Cheung, W. W. L., Dutra, L., et al. 2017. Decadal scale projection of changes in Australian fisheries stocks under climate change. CSIRO, Australia, Australia. 180 pp.

Hamilton, N. E., and Ferry, M. 2018. ggtern: Ternary diagrams using ggplot2. Journal of Statistical Software, 87.

Hare, J. A., Morrison, W. E., Nelson, M. W., Stachura, M. M., Teeters, E. J., Griffis, R. B., Alexander, M. A., et al. 2016. A Vulnerability Assessment of Fish and Invertebrates to Climate Change on the Northeast U.S. Continental Shelf. Plos One, 11: e0146756.

Hassan, R. M., Scholes, R., and Ash, N. 2005. Ecosystems and Human Well-being - Current State and Trends: Findings of the Condition and Trends Working Group of the Millennium Ecosystem Assessment. The Millennium Ecosystem Assessment Series (v. 1): xxi, 917.

Hobday, A. J., Spillman, C. M., Eveson, J. P., Hartog, J. R., Zhang, X., and Brodie, S. 2018. A Framework for Combining Seasonal Forecasts and Climate Projections to Aid Risk Management for Fisheries and Aquaculture. Frontiers in Marine Science, 5: 1-9.

Hoefnagel, E., de Vos, B., and Buisman, E. 2015. Quota swapping, relative stability, and transparency. Marine Policy, 57: 111-119. Elsevier.

IPCC. 2019. IPCC Special Report on the Ocean and Cryosphere in a Changing Climate. In press pp.

Johnson, J. E., Welch, D. J., Maynard, J. A., Bell, J. D., Pecl, G., Robins, J., and Saunders, T. 2016. Assessing and reducing vulnerability to climate change: Moving from theory to practical decisionsupport. Marine Policy, 74: 220-229. Elsevier Ltd.

Jones, M. C., and Cheung, W. W. L. 2018. Using fuzzy logic to determine the vulnerability of marine species to climate change. Global Change Biology, 24: e719-e731.

Kasperski, S., and Holland, D. S. 2013. Income diversification and risk for fishermen. Proceedings of the National Academy of Sciences of the United States of America, 110: 2076-2081.

Kesner-Reyes, K., Kaschner, S., Kullander, Garilao, C., Barile, J., and Froese, R. 2012. AquaMaps: algorithm and data sources for aquatic organisms. www.fishbase.org (Accessed 1 May 2020).

Kjesbu, O. S., Bogstad, B., Devine, J. a, Gjøsæter, H., Howell, D., Ingvaldsen, R. B., Nash, R. D. M., et al. 2014. Synergies between climate and management for Atlantic cod fisheries at high latitudes. Proceedings of the National Academy of Sciences of the United States of America, 111: 3478-83.

Lindegren, M., and Brander, K. 2018. Adapting Fisheries and Their Management To Climate Change: A Review of Concepts, Tools, Frameworks, and Current Progress Toward Implementation. Reviews in Fisheries Science and Aquaculture, 26: 400-415. Taylor \& Francis.

McIlgorm, A., Hanna, S., Knapp, G., Le Floc'H, P., Millerd, F., and Pan, M. 2010. How will climate change alter fishery governance? Insights from seven international case studies. Marine Policy, 34: 170-177. Pergamon. 
Monnereau, I., Mahon, R., Mcconney, P., Nurse, L., Turner, R., and Vallés, H. 2015. Vulnerability of the fisheries sector to climate change impacts in Small Island Developing States and the Wider Caribbean. CERMES Technical Report No77. University of the West Indies. Barbados. 45 pp.

Monnereau, I., Mahon, R., McConney, P., Nurse, L., Turner, R., and Vallès, H. 2017. The impact of methodological choices on the outcome of national-level climate change vulnerability assessments: An example from the global fisheries sector. Fish and Fisheries, 18: 717-731. Blackwell Publishing Ltd.

Natale, F., Carvalho, N., Harrop, M., Guillen, J., and Frangoudes, K. 2013. Identifying fisheries dependent communities in EU coastal areas. Marine Policy, 42: 245-252. Pergamon.

Oppenheimer, M., Campos, M., Warren, R., Birkmann, J., Luber, G., O’Neill, B., and Takahashi, K. 2014. Emergent risks and key vulnerabilities. In Climate Change 2014: Impacts, Adaptation, and Vulnerability. Part A: Global and Sectoral Aspects. Contribution of Working Group II to the Fifth Assessment Report of the Intergovernmental Panel on Climate Change, pp. 1039-1099. Ed. by C. Field, V. Barros, D. Dokken, K. Mach, M. Mastrandrea, T. Bilir, and M. Chatterjee. Cambridge University Press, Cambridge, UK and New York.

Palomares, M. L. D., and Pauly, D. 2019. Sealifebase. https://www.sealifebase.ca/.

Payne, M. R., Barange, M., Cheung, W. W. L., MacKenzie, B. R., Batchelder, H. P., Cormon, X., Eddy, T. D., et al. 2016. Uncertainties in projecting climate-change impacts in marine ecosystems. ICES Journal of Marine Science, 73: 1272-1282.

Payne, M. R., Hobday, A. J., MacKenzie, B. R., Tommasi, D., Dempsey, D. P., Fässler, S. M. M., Haynie, A. C., et al. 2017. Lessons from the First Generation of Marine Ecological Forecast Products. Frontiers in Marine Science, 4.

Peck, M. A., and Pinnegar, J. K. 2018. Chapter 5: Climate change impacts, vulnerabilities and adaptations: North Atlantic and Atlantic Arctic marine fisheries. In Impacts of Climate Change on Fisheries and Aquaculture: Synthesis of current knowledge, adaptation and mitigation options., pp. 87-111. FAO Fisheries and Aquaculture Technical Paper No. 627. FAO, Rome.

Pecl, G. T., Ward, T. M., Doubleday, Z. a., Clarke, S., Day, J., Dixon, C., Frusher, S., et al. 2014. Rapid assessment of fisheries species sensitivity to climate change. Climatic Change, 127: 505-520.

Pecuchet, L., Lindegren, M., Hidalgo, M., Delgado, M., Esteban, A., Fock, H. O., Gil de Sola, L., et al. 2017. From traits to life-history strategies: Deconstructing fish community composition across European seas. Global Ecology and Biogeography, 26: 812-822.

Perry, A. L., Low, P. J., Ellis, J. R., and Reynolds, J. D. 2005. Climate Change and Distribution Shifts in Marine Fishes. Science, 308: 1912-1915.

Perry, A. L. 2005. Climate Change and Distribution Shifts in Marine Fishes. Science, 308: 1912-1915.

Petitgas, P., Rijnsdorp, A. D., Dickey-Collas, M., Engelhard, G. H., Peck, M. A., Pinnegar, J. K., Drinkwater, K., et al. 2013. Impacts of climate change on the complex life cycles of fish. Fisheries Oceanography, 22: 121-139.

Phillips, B., and Pérez-Ramírez, M. 2018. Climate Change Impacts on Fisheries and Aquaculture: A Global Analysis. John Wiley and Sons Inc.

Pinnegar, J. K., Engelhard, G. H., Norris, N. J., Theophille, D., and Sebastien, R. D. 2019. Assessing vulnerability and adaptive capacity of the fisheries sector in Dominica: long-term climate change and catastrophic hurricanes. ICES Journal of Marine Science, 76: 1353-1367. Oxford Academic.

Pinnegar, J. K., Wright, P. J., Maltby, K., and Garrett, A. 2020. The impacts of climate change on fisheries, relevant to the coastal and marine environment around the UK. MCCIP Science Review 
2020: 456-481.

Pinsky, M. L., and Mantua, N. 2014. Emerging Adaptation Approaches for Climate-Ready Fisheries Management. Oceanography, 27: 146-159.

Pinsky, M. L., Reygondeau, G., Caddell, R., Palacios-Abrantes, J., Spijkers, J., and Cheung, W. W. L. 2018. Preparing ocean governance for species on the move. Science, 360: 1189-1191.

Pinsky, M. L., Eikeset, A. M., McCauley, D. J., Payne, J. L., and Sunday, J. M. 2019. Greater vulnerability to warming of marine versus terrestrial ectotherms. Nature. Springer US.

Pinsky, M. L., Fenichel, E., Fogarty, M., Levin, S., McCay, B., St. Martin, K., Selden, R. L., et al. 2020. Fish and fisheries in hot water: What is happening and how do we adapt? Population Ecology. John Wiley and Sons Inc.

Planque, B., Fromentin, J.-M., Cury, P., Drinkwater, K. F., Jennings, S., Perry, R. I., and Kifani, S. 2010. How does fishing alter marine populations and ecosystems sensitivity to climate? Journal of Marine Systems, 79: 403-417. Elsevier B.V.

Poloczanska, E. S., Brown, C. J., Sydeman, W. J., Kiessling, W., Schoeman, D. S., Moore, P. J., Brander, K. M., et al. 2013. Global imprint of climate change on marine life. Nature Climate Change, 3: 919925.

Rijnsdorp, A. D., Peck, M. A., Engelhard, G. H., Möllmann, C., and Pinnegar, J. K. 2009. Resolving the effect of climate change on fish populations. ICES Journal of Marine Science, 66: 1570-1583.

Rogers, L. A., Griffin, R., Young, T., Fuller, E., St. Martin, K., and Pinsky, M. L. 2019. Shifting habitats expose fishing communities to risk under climate change. Nature Climate Change, 9: 512-516. Springer US.

Simpson, S. D., Jennings, S., Johnson, M. P., Blanchard, J. L., Schön, P.-J., Sims, D. W., and Genner, M. J. 2011. Continental shelf-wide response of a fish assemblage to rapid warming of the sea. Current biology $\square: \mathrm{CB}, 21:$ 1565-70.

Spencer, P. D., Hollowed, A. B., Sigler, M. F., Hermann, A. J., and Nelson, M. W. 2019. Trait $\square$ based climate vulnerability assessments in data $\square$ rich systems: An application to eastern Bering Sea fish and invertebrate stocks. Global Change Biology, 25: 3954-3971. Blackwell Publishing Ltd.

STECF. 2018. The 2018 Annual Economic Report on the EU Fishing Fleet (STECF 18-07). Publications Office of the European Union, Luxembourg. $434 \mathrm{pp}$.

Sunday, J. M., Bates, A. E., Kearney, M. R., Colwell, R. K., Dulvy, N. K., Longino, J. T., and Huey, R. B. 2014. Thermal-safety margins and the necessity of thermoregulatory behavior across latitude and elevation. Proceedings of the National Academy of Sciences of the United States of America, 111: 5610-5615. National Academy of Sciences.

Young, T., Fuller, E. C., Provost, M. M., Coleman, K. E., St. Martin, K., McCay, B. J., and Pinsky, M. L. 2019. Adaptation strategies of coastal fishing communities as species shift poleward. ICES Journal of Marine Science, 76: 93-103. 